Jurnal Kebidanan Terkini (Current Midwifery Journal)

e-ISSN 0000-0000

https://jom.htp.ac.id/index.php/jkt

\title{
ASUHAN KEBIDANAN PADA IBU HAMIL TRIMESTER III DENGAN ENDORPHIN MASSAGE UNTUK MENGURANGI NYERI PUNGGUNG DI PMB DELIANA SARAGIH KOTA PEKAN BARU TAHUN 2020
}

\author{
Fera Safitri ${ }^{1}$, Liva Maita ${ }^{2}$ \\ STIKes Hangtuah Pekanbaru \\ 1)ferasafitri1999@gmail.com
}

\section{Histori artikel}

Received:

15 Desember 2020

Accepted:

15 Februari 2021

Published:

16 Maret 2021

\begin{abstract}
Abstrak
Nyeri punggung adalah nyeri yang di rasakan di bagian punggung yang berasal dari otot, persarafan, tulang sendi, atau strukturlain di daerah tulang belakang.Pada Ibu hamil yang mengalami ketidaknyamanan nyeri punggung mencapai $68 \%$ dengan intensitas sedang, dan 32\% ibu hamil mengalami nyeri punggung dengan intensitas ringan. Sebagian besar ibu hamil yang mengalami nyeri punggung disebabkan terjadinya adaptasi anatomis, fisiologi dalam tubuh ibu hamil, termasuk sistem musculoskeletal, dengan bertambahnya berat badan secara bertahap selama kehamilan dan redistribusi pemusatan terdapat pengaruh hormonal pada struktur ligament. Kedua faktor ini merubah postur tubuh ibu hamil menjadikan lordosis, yang kemudian akan berisiko nyeri punggung. Laporan tugas akhir ini bertujuan untuk megetahui pengaruh pemberian endorphin massage pada ibu hamil trimester III dengan nyeri punggug dengan minimal 3 kali kunjungan. Metode yang dipakai yaitu dengan pendekatan manajemen kebidanan kemudian didokumentasikan dalam bentuk SOAP. Tugas akhir dilakukan di rumah pasien di wilayah kerja PMB Deliana Saragih.Setelah dilakukan asuhan kebidanan dengan endorphin massage terdapat pengurangan nyeri punggung.
\end{abstract}

Kata kunci : Asuhan Kebidanan, Ibu Hamil, Endorphin massage 


\section{PENDAHULUAN}

Kehamilan menurut Federasi Obstetri Ginekologi Internasional, adalah sebagai fertilisasi atau penyatuan dari spermatozoa dan ovum dan dilanjutkan dengan nidasi atau implantasi. Bila dihitung dari fertilisasi sampai lahirnya bayi, kehamilan normal akan berlangsung dalam waktu 40 minggu atau 9 bulan menurut kalender internasional. Kehamilan terbagi dalam 3 trimester, dimana trimester kesatu berlangsung dalam 12 minggu, trimester kedua 15 minggu, dan trimester ketiga 13 minggu (Prawirohardjo, 2010).

Selama kehamilan terjadi adaptasi anatomis, fisiologi dalam tubuh ibu hamil, termasuk sistem musculoskeletal. Sejalan dengan bertambahnya berat badan secara bertahap selama kehamilan dan redistribusi pemusatan terdapat pengaruh hormonal pada struktur ligament. Kedua faktor ini merubah postur tubuh ibu hamil menjadikan lordosis, yang kemudian akan berisiko nyeri punggung (Cuningham, 2013) dalam (Ulfah \& Netra, 2017)

Nyeri punggung pada ibu hamil disebabkan oleh hormon estrogen dan progesteron yang mengendurkan sendi, ikatan tulang dan otot di panggul. Pada kehamilan berkaitan dengan regangan yang disebabkan oleh uterus yang membesar (Baiq Eka Putri Saudia \& Sari, 2018)

Nyeri punggung pada ibu hamil jika tidak ditangani dengan baik maka akan berlanjut dalam bentuk cidera kambuhan atau muncul terus menerus dengan perjalanan usia kehamilannya (kantonis, 2011) dalam (Resmi et al., 2017).

Terapi nyeri punggung dapat dilakukan secara farmakologis maupun non farmakologis, salah satu terapi nyeri secara non farmakologis adalah dengan endorphin massage. (kuswandi 2011) dalam (Diana, 2019)

Endorphin massage adalah merupakan sebuah terapi sentuhan/pijatan ringan yang dapat merangsang tubuh untuk melepaskan senyawa endorphin yang merupakan pereda rasa sakit dan dapat menciptakan perasaan nyaman. (Irawati, 2018).

\section{METODE STUDI KASUS}

Metode yang penulis gunakan yaitu dengan cara melakukan asuhan kebidanan sesuai dengan prosedur yang baik dan benar, meliputi menganjurkan ibu untuk melakukan endorphin massage pada Ny. "W" umur 31 tahun G3P2A0H2, dilaksanakan di PMB Deliana Saragih, kemudian dilanjutkan dengan kunjungan rumah pada tanggal 28-30 September 2020.Serta dilakukan pengukuran nyeri punggung di hari pertama dan terakhir dengan skala nyeri NRS. Jenis data primer Cara pengumpulan data anamnesa, observasi,pemeriksaan dan 
dokumentasi. Analisa data dengan membandingkan antara data yang diperoleh dengan teori yang ada.

\section{HASIL STUDI KASUS}

\section{Kunjungan ke-I padaNy. W}

Hari/ Tanggal :jumat/ 28 Agustus 2020 Pukul : 10.00 wib

\section{Data Subjektif}

Ingin memeriksa kehamilannya, Ibu mengatakn bekerja sebagai ibu rumah tangga, Kehamilan yang ketiga, Tidak pernah keguguran, HPHT 10/12/2019, Ibu mengatakan mengalami nyeri punggung karna aktivitas sehari-hari., lbu dapat menunjukkan lokasi nyeri punggung, skala nyeri berada di titik skala 5 yaitu nyeri sedang.

\section{Data Objektif}

Keadaan umum ibu baik dan kesadaran composmentis, Tanda-tanda vital, Tekanan darah :110/70 mmHg, Nadi : $81 \mathrm{x} /$ menit, Pernapasan $\quad: 20 \mathrm{x} /$ menit, Suhu : 36, 5 C, BB sebelum hamil : $45 \mathrm{~kg}$, BB sekarang : $55 \mathrm{~kg}$, Tinggi badan : $156 \mathrm{~cm}$, Lila : $25 \mathrm{~cm}$, TFU $31 \mathrm{~cm}$, presentasi kepala,bisa digoyangkan, DJJ : 135x/menit. Palpasi punggung:Apabila punggung ibu ditekan ibu tampak merasa nyeri.

\section{Assesment}

G3P2A0 Usia kehamilan 36 minggu, dengan nyeri punggung,

Janin hidup, tunggal,preskep.

\section{Plan}

Informasi, edukasi dan terapi :

1. Informasikan hasil pemeriksaan

2. Ketidaknyamanan trimester III

3. Anjurkan ibu untuk mempertahankan postur tubuh yang baik

4. Cara mengatasi nyeri punggung

5. Pemberian endorphin massage

6. tanda-tanda persalinan

7. Anjurkan ibu untuk melakukan endorphin massage

8. Jadwal kunjungan ulang

\section{Lembar implementasi}

Edukasi dan informasi 
1. Menginformasikan bahwa keadaan umum ibu baik, TD: $110 / 70 \mathrm{mmHg}, \mathrm{N}: 81 \mathrm{x} / \mathrm{menit}$, $\mathrm{R}$ : $20 \mathrm{x} / \mathrm{menit}, \mathrm{S}: 36,5^{\circ} \mathrm{C}$, dan kedaan janin dalam batas normal

2. Ketidaknyamanan pada trimester III salah satunya nyeri punggung, nyeri punggung merupakan sesuatu yang fisiologis atau hal yang wajar terjadi pada hamil lanjut. karena nyeri punggung disebabkan oleh pertumbuhan janin, postur tubuh dan perubahan hormon.

3. Menganjurkan ibu untuk mempertahankan postur tubuh yang baik seperti : postur tubuh saat berjalan harus dengan kepala tegak, punggung tegak,dan abdomen dibusungkan, membungkuk dan membawa beban harus dihindari dan tekuk lutut saat mengangkat benda.

4. Memberitahu ibu cara mengatasi nyeri punggung dengan melakukan endorphin massage, karena manfaat endorphin masssagemengendalikan rasa nyeri serta sakit, membuat ibu nyaman dan rileks

5. Menjelaskan kepada suami cara melakukan endorphin massage yaitu:
a. Alat yang dibutuhkan minyak zaitun
b. Penatalaksanaan endorphin massage

\section{Cara 1:}

1) Suami meminta calon bunda (istri) untuk berbaring atau duduk dengan posisi senyaman mungkin. Adapun posisi suami adalah berada di dekat calon bunda (duduk di samping atau di belakang).

2) Suami meminta calon bunda untuk menarik napas yang dalam lalu keluarkan dengan lembut sambil memejamkan mata. Kemudian, suami memulai mengelus permukaan luar lengan calon bunda, mulai dari tangan sampai lengan bawah.Sentuhan atau pijatan ringan ini cukup dilakukan menggunakan jari-jemari atau hanya ujung-unjung jari saja.

3) Lakukan sentuhan atau pijatan ringan selama kurang lebih 5 menit. Setelah itu, suami baru boleh berpindah pada lengan atau tangan atau bagian tubuh lain.

\section{Cara 2 :}

1) Setelah menemukan posisi yang betul-betul nyaman, memberikan sentuhan ringan kepada calon bunda dengan lembut. Sentuhan atau pijatan ringan ini dapat dimulai dari arah leher membentuk $\mathrm{V}$ terbalik, ke arah luar menuju sisi tulang rusuk, sambil di pijat memutar dengan ibu jari.

2) Terus lakukan pijatan-pijatan ringan ini hingga ketubuh bagian bawah belakang calon bunda. 
3) Untuk memperkuat efek dari sentuhan ini, suami juga dapat memberikan sugesti dengan kata-kata yang menenteramkan, sambil mengelus perut si bunda.

4) Setelah melakukan endorphin massage, sebaik-baiknya suami langsung memeluk calon bunda, sehingga tercipta suasana yang benar-benar menenangkan.

5) Menjelaskan tanda-tanda bahaya kehamilan trimester III yaitu sakit kepala hebat,demam tinggi, pendarahan, ketuban pecah sebelum waktunya, gerakan janin berkurang, bengkak pada kaki dan wajah.

6) Menjelaskan tanda-tanda persalinan yaitu keluar lendir bercampur darah, adanya kontraksi yang teratur dan kuat, ketuban pecah.

7) Menganjurkan ibu untuk melakukan endorphin massage boleh setiap hari sat ibu merasaan nyeri punggung.

8) Menyepakati kunjungan ulang tanggal 29-08-2020.

\section{Kunjungan ke-II padaNy. W}

Hari/ Tanggal :sabtu/ 29 Agustus 2020 Pukul : 09.30 wib

\section{Data Subjektif}

Ibu mengatakan nyeri punggun sudah berkurang, skala nyeri berada di titik skala 4 yaitu nyeri sedang, Ibu melakukan endorphin massage pada malam hari.

\section{Data Objektif}

Keadaan umum ibu baik dan kesadaran composmentis, Tanda-tanda vital, Tekanan darah :110/70 mmHg, Nadi : 80 x/menit, Pernapasan: 20 x/menit, Suhu : $36,8^{\circ} \mathrm{C}$.

\section{Assasment}

G3P2A0 Usia kehamilan 36 minggu, dengan nyeri punggung,

Janin hidup, tunggal,preskep.

\section{Plan}

1) Informasi, edukasi, terapi

2) Informasi hasil pemeriksaan

3) Lakukan kembali endorphin massage

4) Kunjungan ulang

\section{Lembar implementasi}

Edukasi dan informasi

1) Menginformasikan bahwa keadaan umum ibu baik, TD: $110 / 70 \mathrm{mmHg}, \mathrm{N}: 80 \mathrm{x} / \mathrm{menit}$, R: $20 \mathrm{x} /$ menit, S: $36,8^{\circ} \mathrm{C}$, dan kedaan janin dalam batas normal. 
2) Melakukan kembali gerakan endorphin massage, yaitu:

3) Alat yang dibutuhkan minyak zaitun

4) Penatalaksanaan endorphin massage

Cara 1:

1) Suami meminta calon bunda (istri) untuk berbaring atau duduk dengan posisi senyaman mungkin. Adapun posisi suami adalah berada di dekat calon bunda (duduk di samping atau di belakang).

2) Suami meminta calon bunda untuk menarik napas yang dalam lalu keluarkan dengan lembut sambil memejamkan mata. Kemudian, suami memulai mengelus permukaan luar lengan calon bunda, mulai dari tangan sampai lengan bawah.Sentuhan atau pijatan ringan ini cukup dilakukan menggunakan jari-jemari atau hanya ujung-unjung jari saja.

3) Lakukan sentuhan atau pijatan ringan selama kurang lebih 5 menit. Setelah itu, suami baru boleh berpindah pada lengan atau tangan atau bagian tubuh lain.

Cara 2 :

1) Setelah menemukan posisi yang betul-betul nyaman, memberikan sentuhan ringan kepada calon bunda dengan lembut. Sentuhan atau pijatan ringan ini dapat dimulai dari arah leher membentuk $\mathrm{V}$ terbalik, ke arah luar menuju sisi tulang rusuk, sambil di pijat memutar dengan ibu jari.

2) Terus lakukan pijatan-pijatan ringan ini hingga ketubuh bagian bawah belakang calon bunda.

3) Untuk memperkuat efek dari sentuhan ini, suami juga dapat memberikan sugesti dengan kata-kata yang menenteramkan, sambil mengelus perut si bunda.

4) Setelah melakukan endorphin massage, sebaik-baiknya suami langsung

5) memeluk calon bunda, sehingga tercipta suasana yang benar-benar menenangkan.

6) Menyepakati kunjungan ulang tanggal 30-08-2020.

\section{Kunjungan ke-III padaNy. W}

Hari/ Tanggal :sabtu/ 30 Agustus 2020 Pukul : 10.09 wib

\section{Data Subjektif}

Nyeri pada punggung sudah berkurang, skala nyeri berada di titik skala 2 yaitu nyeri ringan. Ibu melakukan endorphin massage pada malam hari.

Data objektif

Keadaan umum ibu baik dan kesadaran composmentis, Tanda-tanda vital, Tekanan darah :110/70 mmHg, Nadi : 80 x/menit, Pernapasan: 20 x/menit, Suhu : 36, $8^{\circ} \mathrm{C}$. 


\section{Assesment}

G3P2A0 Usia kehamilan 36 minggu, dengan nyeri punggung,

Janin hidup, tunggal,preskep.

\section{Plan}

1) Informasi, edukasi, terapi

2) Informasi hasil pemeriksaan

3) Lakukan kembali cara endorphin massage

4) Kunjungan ulang.

\section{Lembar implementasi}

Edukasi, dan informasi

Menginformasikan bahwa keadaan umum ibu baik, TD: 110/70 mmHg, N: $80 x / m e n i t, ~ R$ : $20 x /$ menit, S: $36,5^{\circ}$, dan kedaan janin dalam batas normal.

Melakukan kembali gerakan endorphin massage, yaitu:

Alat yang dibutuhkan minyak zaitun

Penatalaksanaan endorphin massage

Cara 1:

1) Suami meminta calon bunda (istri) untuk berbaring atau duduk dengan posisi senyaman mungkin. Adapun posisi suami adalah berada di dekat calon bunda (duduk di samping atau di belakang).

2) Suami meminta calon bunda untuk menarik napas yang dalam lalu keluarkan dengan lembut sambil memejamkan mata. Kemudian, suami memulai mengelus permukaan luar lengan calon bunda, mulai dari tangan sampai lengan bawah.Sentuhan atau pijatan ringan ini cukup dilakukan menggunakan jari-jemari atau hanya ujung-unjung jari saja.

3) Lakukan sentuhan atau pijatan ringan selama kurang lebih 5 menit. Setelah itu, suami baru boleh berpindah pada lengan atau tangan atau bagian tubuh lain.

Cara 2 :

1) Setelah menemukan posisi yang betul-betul nyaman, memberikan sentuhan ringan kepada calon bunda dengan lembut. Sentuhan atau pijatan ringan ini dapat dimulai dari arah leher membentuk $\mathrm{V}$ terbalik, ke arah luar menuju sisi tulang rusuk, sambil di pijat memutar dengan ibu jari.

2) Terus lakukan pijatan-pijatan ringan ini hingga ketubuh bagian bawah belakang calon bunda.

3) Untuk memperkuat efek dari sentuhan ini, suami juga dapat memberikan sugesti dengan kata-kata yang menenteramkan, sambil mengelus perut si bunda. 
4) Setelah melakukan endorphin massage, sebaik-baiknya suami langsung memeluk calon bunda, sehingga tercipta suasana yang benar-benar menenangkan.

5) Menganjurkan ibu untuk kunjungan ulang secara rutin 2 minggu sekali atau jika ada keluhan.

\section{PEMBAHASAN}

\section{Data Subjektif}

Data subjektif yang ditemukan pada kajian 1 terdapat informasi tentang $\mathrm{Ny}$. W mengatakan usia 31 tahun, ibu mengatakan mengeluh nyeri punggung dengan skala nyeri berada diskala 5 yaitu nyeri sedang, ibu dapat menunjukkan lokasi nyeri punggung yaitu pada punggung bagian bawah, subjektif tersebut terdapat informasi tentang Ny. W mengatakan usia 31 tahun, ibu mengatakan mengeluh nyeri punggung dengan skala nyeri berada diskala 5 yaitu nyeri sedang, ibu dapat menunjukkan lokasi nyeri punggung yaitu pada punggung bagian bawah, sehingga pada evaluasi hari terakhir ibu mengatakan nyeri punggung yang dialaminya sudah berkurang dan skala nyeri punggung berada di skala 2 .

Menurut (Baiq Eka Putri Saudia \& Sari, 2018) Nyeri punggung pada ibu hamil disebabkan oleh hormon estrogen dan progesteron yang mengendurkan sendi, ikatan tulang dan otot dipanggul pada kehamilan berkaitan dengan regangan yang disebabkan oleh uterus yang membesar.

\section{Data Objektif}

Data objektif dari asuhan pada Ny. W kunjungan I yaitu keadaan umum ibu baik, tekanan darah $110 / 70 \mathrm{mmHg}$, denyut nadi $80 x / \mathrm{i}$, pernapasan $21 \mathrm{x} / \mathrm{i}$ dan suhu $36,5 \mathrm{c}$.Pada pemeriksaan fisik penulis tidak menemukan kesenjangan antara teori dengan kasus.

\section{Assasment}

Diagnosis yang dapat ditegakkan pada asuhan kebidanan ini adalah G3P2A0 usia kehamilan 36 minggu dengan nyeri punggung, janin hidup tunggal, preskep.

\section{Plan}

Planning pada kasus ini penulis memberikan pendidikan kesehatan tentang nyeri punggung, jadi untuk mengatasi nyeri punggung tersebut penulis mencoba memberikan endorphin massage untuk mengurangi nyeri punggung.

Menurut (kuswandi, 2011) dalam (Diana, 2019) Terapi nyeri punggung dapat dilakukan secara farmakologis maupun non farmakologis, salah satu terapi nyeri secara non farmakologis adalah dengan endorphin massage.Endorphin massage adalah merupakan sebuah terapi sentuhan/pijatan ringan yang dapat merangsang tubuh untuk melepaskan 
senyawa endorphin yang merupakan pereda rasa sakit dan dapat menciptakan perasaan nyaman (Irawati, 2018).

Penulis menjadwalkan 3 kali kunjungan di rumah pasien. Pada kunjungan yang terakhir ibu mengatakan bahwa nyeri punggung yang dialaminya sudah berkurang dikarenaan ibu menjalani atau melakukan dengan baik asuhan yang telah diberikan.

\section{KESIMPULAN}

Asuhan Kebidanan Pada Ibu Hamil Trimester III Dengan Endorphin Massage Untuk Mengurangi Nyeri Punggung di BPM Deliana Saragih dengan 3 kali kunjungan rumah. Berdasarkan apa yang telah penulis dapatkan dengan pendokumentasian SOAP (Subjektif, Objektif,Assasment,Penatalaksanaan), setelah mengumpulkan data secara keseluruhan dapat dibuat kesimpulan yaitu:

Setelah penulis mendapatkan persetujuan pasien bahwa akan dilakukan asuhan, penulis dapat mengumpulkan data subjektif dan data objektif. Saat melakukan pengumpulan data penulis tidak mengalami kesulitan karena pasien bersedia untuk bekerja sama. Penulis tidak menemukan kesenjangan pada hasil data subjektif dan data objektif. Sehingga semua data terkumpul penulis dapat menyimpulkan analisis sesuai dengan data yang telah dikumpulkan. Assasment pada pemeriksaan pertama yaitu G3P2A0 Usia kehamilan 36 minggu dengan nyeri punggung, janin hidup tunggal preskep, keadaan umum ibu dan janin baik. Setelah dilakukan asuhan kebidanan selama 3 kali kunjungan ke rumah pasien ibu mengatakan nyeri punggung berada di skala 2, maka hasil yang didapatkan pada kajian terakhir yaitu nyeri punggung yang dialami ibu dapat berkurang.

\section{SARAN}

1. Bagi PMB Deliana Saragih

a. Diharapkan kepada penyedia tempat pelayanan asuhan kebidanan yang sedang menjalankan praktik untuk dapat melakukan penyuluhan kepada ibu hamil khususnya dengan nyeri punggung pada trimester III agar ketidaknyamanan pada ibu hamil dapat di atasi.

b. Diharapkan kepada PMB Deliana Saragihuntuk memberikan asuhan tentang teknik endorphin massage.

2. Bagi STIKes Hang Tuah Pekanbaru

a. Dapat menambah sumber wawasan pengetahuan mahasiswa di STIKes Hang Tuah jurusan DIII Kebidanan. 
b. Diharapkan sebagai referensi pengembang ilmu pengetahuan tentang asuhan kebidanan pada ibu hamil dan menjadi pedoman untuk studi kasus berikutnya.

3. Bagi Mahasiswa

a. Diharapkan studi kasus ini dapat dijadikan pedoman atau informasi dan menambah pengetahuan penulis selanjutnya yang akan melakukan studi kasus yang serupa.

b. Perlunya dilaksanakan pelayanan kebidanan yang berkelanjutan bagi mahasiswa dalam memberikan asuhan kebidanan pada ibu hamil.

\section{DAFTAR PUSTAKA}

Baiq Eka Putri Saudia, \& Sari, O. N. K. (2018). PERBEDAAN EFEKTIVITAS ENDORPHIN MASSAGE DENGAN KOMPRES HANGAT TERHADAP PENURUNAN NYERI PUNGGUNG IBU HAMIL TRIMESTER III DI PUSKESMAS WILAYAH KERJA SEKOTA MATARAM. I(October 2017), 23-29.

Diana, W. (2019). Endorphin Massage Efektif Menurunkan Nyeri Punggung lbu Hamil Trimester lii. Journal of Health Sciences, 12(02), 62-70. https://doi.org/10.33086/jhs.v12i02.1128

Irawati, A. (2018). Pengaruh Endorphin Masase Terhadap Rasa Nyaman Selama Proses Persalinan di Puskesmas Mahalona Kabupaten Luwu Timur. Journal of Chemical Information and Modeling, 53(9), 1-7. https://doi.org/10.1017/CBO9781107415324.004

Prawirohardjo, S. (2010). ILMU KEBIDANAN Sarwono Prawirohardjo. PT Bina Pustaka Sarwono.

Resmi, D. C., Hadi, S., Saputro, \& Runjati. (2017). PENGARUH YOGA TERHADAP NYERI PUNGGUNG BAWAH PADA IBU HAMIL TRIMESTER III DI PUSKESMAS KALIKAJAR I KABUPATEN WONOSOBOPENGARUH YOGA TERHADAP NYERI PUNGGUNG BAWAH PADA IBU HAMIL TRIMESTER III DI PUSKESMAS KALIKAJAR I KABUPATEN WONOSOBO. 1-10.

Ulfah, M., \& Netra, I. W. (2017). PERBEDAAN MANFAAT SEBELUM DAN SESUDAH LATIHAN PELVIC TILT TERHADAP NYERI PUNGGUNG IBU HAMIL TRIMESTER III Mariah Ulfah 1, Ikit Netra Wirakhmi 11. 15(2), 80-83. 